\title{
Evaluation of Antihyperlipidemic Effect of Ethanol Extract of Balanites Aegyptiaca Fruit in Triton X-100 Induce Hyperlipidemic Rats Animal Models
}

\author{
Mohammed Adam Idris Hamad", Dr.Rama Nargund** \\ Department of pharmacology,Nargund college of pharmacy \\ DOI: 10.29322/IJSRP.12.01.2022.p12127 \\ http://dx.doi.org/10.29322/IJSRP.12.01.2022.p12127
}

\begin{abstract}
The major risk factor of cardio vascular disease is related to disturbances in lipids profile result in hyperlipidemia1 . Our present study is to evaluate antihyperlipidemic effect of ethanol extract of balanites aegyptiaca fruit (EEBAF) in Triton x100 induce hyperlipidemic rats in animal models. The Triton X100 solution $100 \mathrm{mg} / \mathrm{kg}$ it is used to induced hyperlipidemia by elevating serum triglyceride in animals models 2 . Treatment with ethanol extract of balanites aegyptiaca $200 \mathrm{mg}$ and $400 \mathrm{mg}$ dose significantly decreased in Tc ,TG, \& LDL-c serum levels and increased in HDL-c serum levels when compared to hyperlipidemic treated rats. The redaction in HDL-c is one major factors of pathogenesis of atherosclerosis. After administration of EEBAF result increased in HDL-c levels. We could conclude that the EEBAF having good cardio -protective agent this effect due Phenolics and Flavonoids present in EEBAF extract.
\end{abstract}

Index Terms- Hyperlipidemia,Triton X-100, Simvastatin,EEBAF.

\section{INTRODUCTION}

$\mathrm{H}$ yperlipidemia, or hypercholesteromia, it is disorders indicate to elevated levels of lipid profiles in the blood ${ }^{3}$. Thus result in risk of cardio vascular disease consequently lead to atherosclerosis ${ }^{4}$. Some people may not usually experience symptoms but having heart disease and increase the risk of stroke ${ }^{5}$. Two types of lipoproteins, that transport cholesterol to the cells which include Low-density lipoproteins (LDL), it is also termed as bad cholesterol, and high-density lipoproteins (HDL), or good cholesterol. High LDL level leads to a buildup of cholesterol in arteries result in atherosclerosis ${ }^{6}$.

Balanites aegyptiaca it has has been used in a variety of folk medicines ${ }^{7}$. Treatment with EEBAF at 400 and $200 \mathrm{mg} / \mathrm{kg}$ dose significantly reduced the serum Tc, TG, \& LDL-c levels \& increased the serum HDL-c levels when 'compared to hyperlipidemic treated rats (control).

\section{MATERIAL \& METHODS}

\section{a.Plants materials and extraction}

The mesocarp fruits of Balanites aegyptiaca were purchased from Randhawa Farm-Punjab and authenticated letter was received. The mesocarp fruits of Balanites aegyptiaca were subjected to extraction by maceration using ethanol $95 \%$, the mesocarp fruits $(500 \mathrm{~g})$ were immersed in the solvent ethanol $(1000 \mathrm{ml})$ for 6 days with frequent shaking ${ }^{8}$. Then it was filtered, and the filtrate was evaporated. The residue obtained was dried and percentage yield was calculated by the formula9-

$$
\% \text { Yield }=\frac{\text { Actual Yield }}{\text { theoretical Yield }} \times 100 \%
$$

\section{Qualitative test ;}

Qualitative phytochemical tests for the ethanol extract of Balanites aegyptiaca fruit was subjected to qualitative tests for tannins, saponin, flavonoids, terpenoids, phenolic compounds, alkaloids and anthraquinones ${ }^{9}$.

\section{Quantitative test;}

\section{Total phenolic content}

Total phenolic content (TPC) was determined by FolinCiocalteu method ${ }^{10}$.

To $10 \mu 1$ of EEBA, add $50 \mu 1$ of Folin Ciocalteu reagent and shake for $5 \mathrm{~min}$. To the above mixture, add $150 \mu \mathrm{l}$ of $20 \% \mathrm{Na}_{2} \mathrm{CO}_{3}$ and mixed properly and made $3 \mathrm{ml}$ with distilled water. After 90 min, the absorbance was measured at $760 \mathrm{~nm}$ by using UV spectrophotometer $(1600)^{11}$.

Gallic acid was used as a standard for calibration. The phenolic content was expressed as milligram of gallic acid equivalent per gram of dry sample (mg GAE/g) using the linear equation based on the calibration curve ${ }^{12}$.

\section{Total flavonoids content}

One gram of EEBAF was added to $15 \mathrm{ml}$ of ethanol (50\%) and extracted for three times by maceration for $2 \mathrm{~h}$. Then filtered and make up the volume with ethanol (50\%) in volumetric flask up to $100 \mathrm{ml}$.

One $\mathrm{ml}$ aliquot of the sample was taken in a test tube and diluted with $10 \mathrm{ml}$ of distilled water. Add $1.5 \mathrm{ml}$ Folin Ciocalteu's reagent and allowed to incubate at room temperature for $5 \mathrm{~min} .4$ $\mathrm{ml}$ of $20 \%(\mathrm{w} / \mathrm{w}) \mathrm{Na}_{2} \mathrm{CO}_{3}$ was added, adjusted to $25 \mathrm{ml}$ with distilled water, agitated and left to stand for $30 \mathrm{~min}$ at room temperature. The absorbance of the sample was measured at 765 nm against blank ${ }^{13}$ 


\section{CHEMICALS}

All the chemicals and reagents used in the study were of analytical grade and molecular biology grade. Triton X-100 was purchased from Sigma Aldrich chemical private limitedBangalore-India. Reagents for estimation of SGOT, SGPT, lipid profile Purchased from Unitron Bio Medicals, Bangalore- India. Standard drugs Simvastatin where purchased from MedPlus Pharmacy, Bangalore India

\section{ANIMALS \& EXPERIMENTAL DESIGN}

Male Albino Wistar rats weighing $180 \mathrm{~g}-200 \mathrm{~g}^{14}$ were procured from Adita Biosys Pvt Ltd, Bangalore. Animals were housed in polypropylene cages with paddy husk as bedding material. They were provided with standard pellet rodent diet (Amrut Laboratory animal feed, Sangli) and free access to water. We had taken approval from Institution Animals Ethics Committee, Nargund College of Pharmacy, Bangalore. Has approved the experimental protocol (IAEC/NCP/109/2020). All the procedures were performed in accordance with the Committee for the Purpose of Control and supervision of Experiments on Animals (CPCSEA).${ }^{15}$ The biomedical disposal was sent to Maridi Bio Industries Pvt, Ltd, Bangalore .

\section{Anti-hyperlipidemic studies}

The rats were divided into five groups of six rats in each group $(n=6)$. From group II to $\mathrm{V}$ hyperlipidemia was induced by single dose of Triton X-100 (100 mg/kg intraperitoneal injection) over 18 hours fasting rats ${ }^{16}$.

Group- I: Normal control .

Group -II: hyperlipidemic control .

Group- III: standard group (simvastatin $10 \mathrm{mg} / \mathrm{kg}$ ) p.o.

Group -IV: EEBAF (200 mg/ kg) p.o.

Group -V: EEBAF (400 mg / kg) p.o.

After 3 days of hyperlipidemia induced, the rats where treated with EEBAF for 14 days. The high dose of EEBAF where administered at $7 \mathrm{pm}$. (200 mg of EEBAF and $10 \mathrm{mg}$ of simvastatin ) p.o was administered at morning .

\section{Collection of blood:}

After 14 days of treatment over night fasting for 18 hours blood samples were collected in blood collection tubes from all fasted group animals by retro orbital under ether anesthesia. Serum was collected by centrifuging tubes at $4000 \mathrm{rpm}$ for $20 \mathrm{~min}$ in cold centrifuge (Remi C-854/6). After blood collection, all the animals were sacrificed by overdose of anesthesia pentobarbitone (100 $\mathrm{mg} / \mathrm{kg} \mathrm{IP}$ ). Isolate liver, carotid artery washed with ice-cold saline and kept in $10 \%$ formalin solution and sent to histopathology lab Dr. Vamshi's, Biological sciences \& Research CentreBangalore.

\section{Biochemical parameters analysis:}

The serum was stored at $-20^{\circ} \mathrm{C}$ and used further for measured the biochemical parameters such as HDL-cholesterol (HDL-c), Total cholesterol (TC), Triglyceride (TG), Aspartate amino transferase (AST) and Alanine amino transferase (ALT) levels.

\section{Statistical analysis}

All the data were subjected to column statistical analysis so as to obtain the Mean \pm S.E.M values for the group. These values were used to assess the treatments are significant using one way analysis of variance (ANOVA) followed by Dennett's test (Graph Pad Prism 9 for Windows, Version 9.1.2(226). $\mathrm{P}$ value $(\mathrm{P}<0.05)$ and $(\mathrm{P}<0.01)$.

\section{RESULT:}

The mesocarp fruit of EEBAF were found to have percentage yield $34.75 \%$.

\section{Qualitative test}

Table Qualitative phytoconstituents of EEBAF.

\begin{tabular}{|l|l|l|}
\hline S.No & Test & State \\
\hline 1 & Reducing sugar & + \\
\hline 2 & Tannins & - \\
\hline 3 & Steroid & + \\
\hline 4 & Terpenoids & + \\
\hline 5 & Flavonids & + \\
\hline 6 & Saponin & + \\
\hline 7 & Glycoside & + \\
\hline
\end{tabular}

(+ )indicate present of constituent , (- )indicate absent of constituent. 


\section{Quantitative studies (Total Phenolic and Flavonoid content).}

\begin{tabular}{|l|l|l|}
\hline Formulations & Total Phenolic Content $\mathbf{m g} / \mathbf{g}$ & Total Flavonoid Content mg/g \\
\hline EEBAF & $1.04 \pm 0.4$ & $0.58 \pm 0.1$ \\
\hline
\end{tabular}

\section{Effect on lipid profiles}

Ethanol extract of Balanites aegyptiaca fruit $(400 \mathrm{mg} / \mathrm{kg})$ in
$(\mathrm{P}<0.001)$ decreased in Tc, LDL-c, and TG, and increased in HDL-c levels when compared with hyperlipidemic treated rats. Triton X-100 induce hyperlipidemia resulted significantly

Table 1; effect of EEBAF on lipid profiles

$\begin{array}{llllll}\text { Groups } & \text { Control } & \begin{array}{l}\text { Hypperlipidemic } \\ \text { control }\end{array} & \text { Standard group } & \text { EEBAF 200 mg } & \text { EEBAF 400 mg } \\ \text { Tc }(\mathrm{mg} / \mathrm{dl}) & 33.74 \pm 10.5 & 92.86 \pm 16.6 * * & 35.73 \pm 11.5 * * & 46.67 \pm 8.6 * * & 36.30 \pm 12 * * * \\ \text { TG }(\mathrm{mg} / \mathrm{dl}) & 46.40 \pm 12.4 & 120.43 \pm 16.9 * & 44.9 \pm 34.6 * * & 51.6 \pm 12.03 \mathrm{~ns} & 63.37 \pm 10.9 * * \\ \text { HDL }(\mathrm{mg} / \mathrm{dl}) & 28.53 \pm 3.5 & 23.83 \pm 9.2 * * & 26.7 \pm 10.1 * * & 24.73 \pm 4.3 * * & 25.1 \pm 4.8 * * * \\ & & & & 12.9 \pm 9.3 * * * & 12.9 \pm 5.9 * *\end{array}$

All value are expressed as mean \pm SEM and $n=6$ for all group. Simvastatin and EEBAF (200 mg \& $400 \mathrm{mg} / \mathrm{kg}$ ) were compared with Triton X-100 treated group. Data was analyzed using one way ANOVA followed by Dunnett's $t$ test. ns-non significant, $\left(* \mathrm{P}<0.0014,{ }^{*} * * \mathrm{P}<0.0040,{ }^{*} * \mathrm{P}<0.007 . \mathrm{P}<0.0004\right)$

HDL - High density lipoprotein, LDL- Low density lipoprotein, TG- Triglyceride, Tc - Total cholesterol

\section{Effect of Biological rhythms (Chronopharmacological)}

$400 \mathrm{mg}$ of $E E B A F$ dose resulted more significance compared to $200 \mathrm{mg}$ dose at morning times. $E E B A F$ showed significance effect increased antioxidants enzymes when compared to Triton $\mathrm{X}-100$ treated rats.

\section{Liver biomarkers effect:}

The dose of $(E E B A F 400 \mathrm{mg})$ dose significantly $(\mathrm{P}<0.05)$ decreased in SGOT and SGPT levels when compared with Triton X-100 treated rats and mild significantly decreased in Simvastatin treated rats.

Table 2: effect of $E E B A F$ in liver biomarker enzyme

\begin{tabular}{|c|c|c|}
\hline Experimental groups/Treatment & SGOT(U/1) & SGPT (U/1) \\
\hline Normal control & $54.27 \pm 8.80$ & $51.09 \pm 8.26$ \\
\hline Triton X-100,100mg/kg.b.w,I.P & $154.64 \pm 22.29^{* *}$ & $141.1 \pm 10.5^{* * *}$ \\
\hline Triton X-100 + Simvastatin $10 \mathrm{mg} / \mathrm{kg}$, p.o & $51.90 \pm 2.20^{* *}$ & $101.41 \pm 12.7^{*}$ \\
\hline $\begin{array}{l}\text { Triton X-100 }+200 \mathrm{mg} / \mathrm{kg} \text {,b.w.P.o Balanites aegyptiaca } \\
\text { extract }\end{array}$ & $72.30 \pm 20.88^{*}$ & $87.21 \pm 16.6^{* *}$ \\
\hline $\begin{array}{l}\text { Triton X-100 + 400mg/kg.b.w.P.o Balanites aegyptiaca } \\
\text { extract }\end{array}$ & $45.94 \pm 19.12^{* *}$ & $64.43 \pm 12.25^{* * *}$ \\
\hline
\end{tabular}


All value are expressed as mean $\pm S D$ and $n=6$ Data was analyzed using one way ANOVA followed by Dunnett's $t$ test. nsnon significant, $* \mathrm{P}<0.05, * * * \mathrm{P}<0.002$.

\section{Antioxidants enzyme}

Table 3; effect of $E E B A F$ in antioxidants enzyme

\begin{tabular}{|c|c|c|c|}
\hline Experimental groups/Treatment & $\begin{array}{l}\text { SOD(units/mg } \\
\text { protein) }\end{array}$ & $\begin{array}{l}\text { CAT(units/ mg of } \\
\text { protein) }\end{array}$ & $\begin{array}{l}\mathrm{TP} \text { (units/ mg of } \\
\text { protein) }\end{array}$ \\
\hline Normal control & $5.1 \pm 1.12$ & 87.67 & $9.65 \pm 0.66$ \\
\hline Triton X-100,100mg/kg.b.w,I.P & $2.38 .11 \pm 0.4^{* *}$ & $31.69 \pm 4.8^{* *}$ & $13.43 \pm 3.4^{*}$ \\
\hline Triton X-100 + Simvastatin $10 \mathrm{mg} / \mathrm{kg}$, p.o & $4.1 \pm 2.48 *$ & $83.83 .4 \pm 9.4^{* * *}$ & $8.2 \pm 2.9^{*}$ \\
\hline $\begin{array}{l}\text { Triton X-100 }+200 \mathrm{mg} / \mathrm{kg} \text {,b.w.P.o } \\
\text { Balanites aegyptiaca extract }\end{array}$ & $3.2 \pm 5.5^{* *}$ & $61.04 \pm 6.9^{* *}$ & $8.1 \pm 2.5^{*}$ \\
\hline $\begin{array}{l}\text { Triton X-100 }+400 \mathrm{mg} / \mathrm{kg} \text {.b.w.P.o } \\
\text { Balanites aegyptiaca extract }\end{array}$ & $4.03 \pm 5.5^{*}$ & $65.62 \pm 4.5^{* * *}$ & $7.2 \pm 0.7^{*}$ \\
\hline
\end{tabular}

All value are expressed as mean $\pm \mathrm{SD}$ and $n=6$ Data was analyzed using one way ANOVA followed by Dunnett's $t$ test. ns-non significant $\mathrm{P}$.value $\mathrm{P}<0.05,{ }^{*} \mathrm{P}<0.002$.

\section{Histopathological result of liver :}




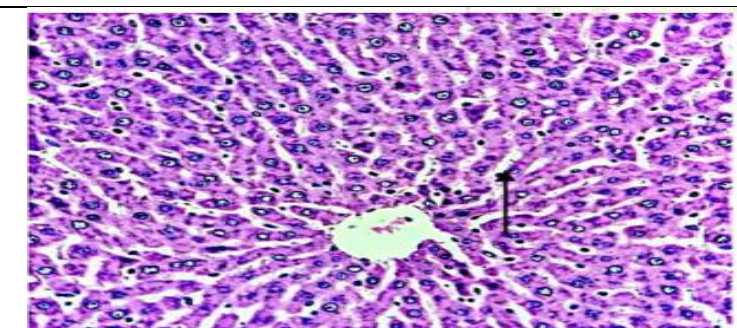

a)

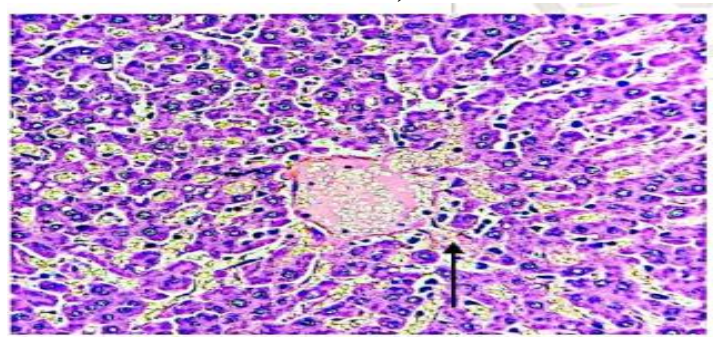

c)

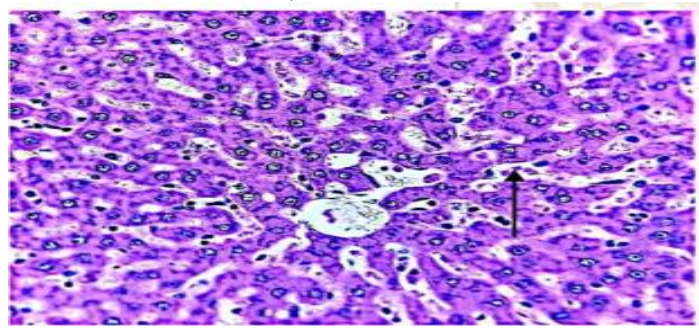

e)

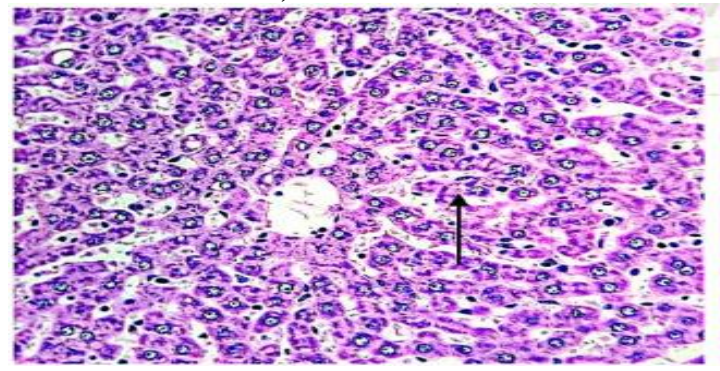

g)

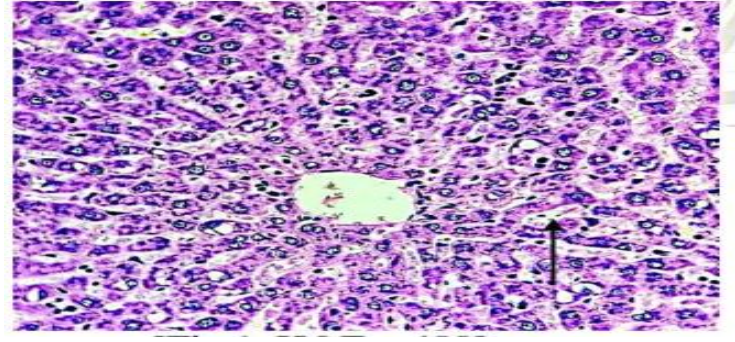

i)

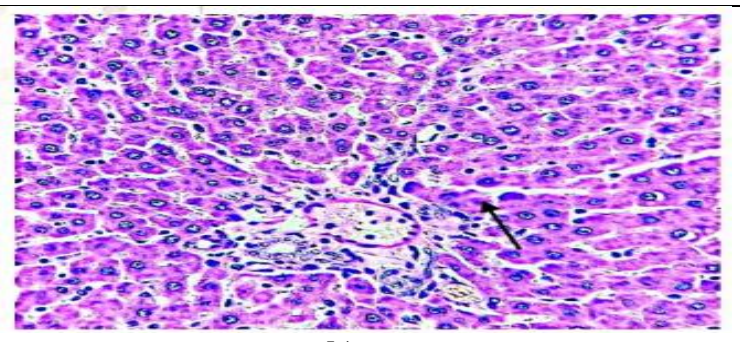

b)

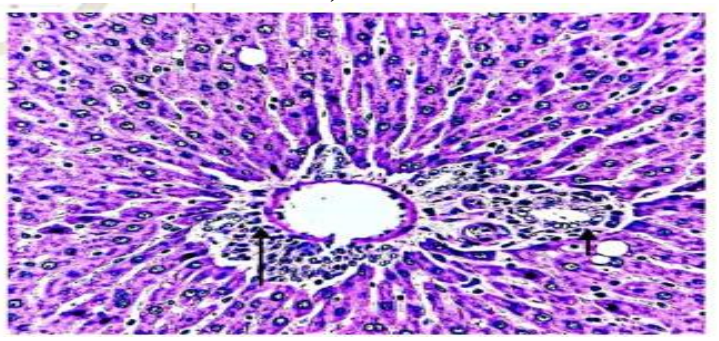

d)

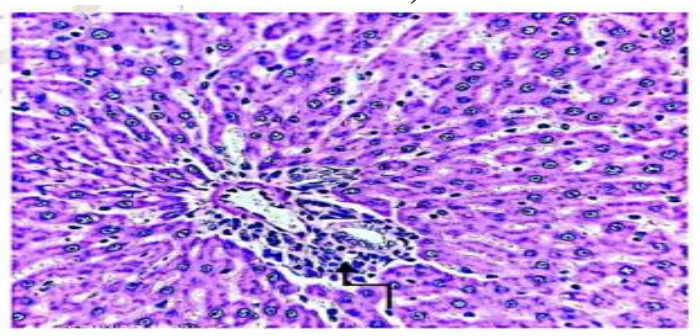

f)

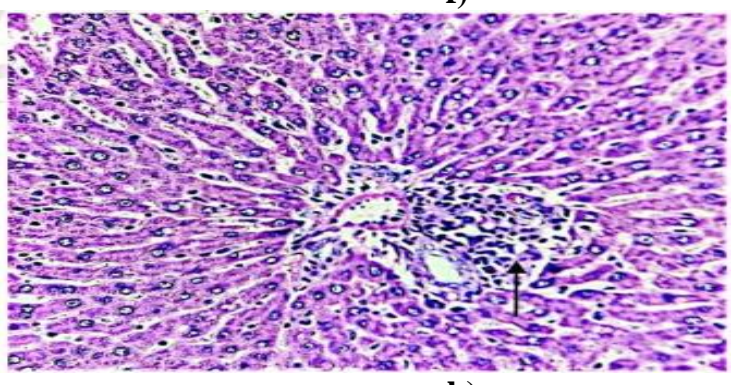

h)

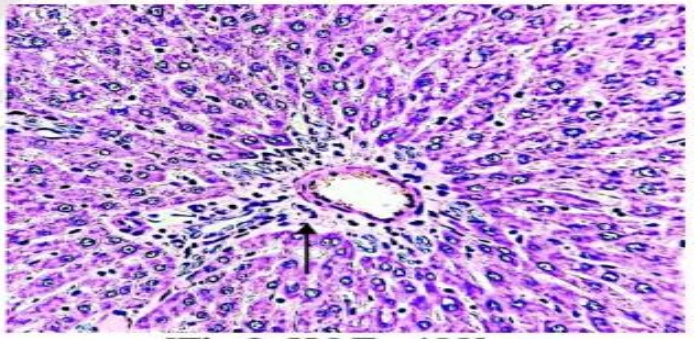

j)

\section{Histopathology result of artery:}




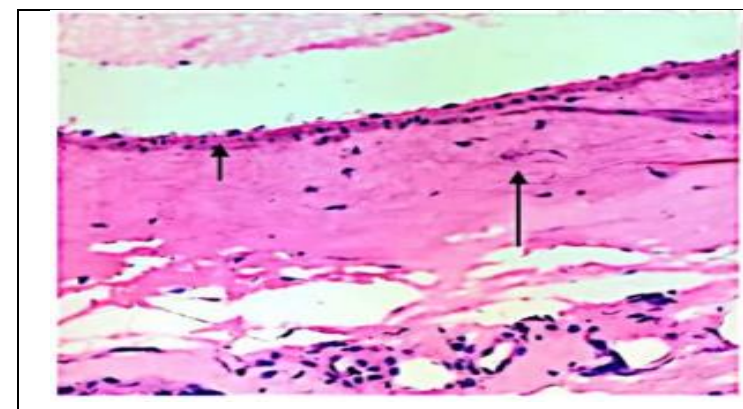

a)

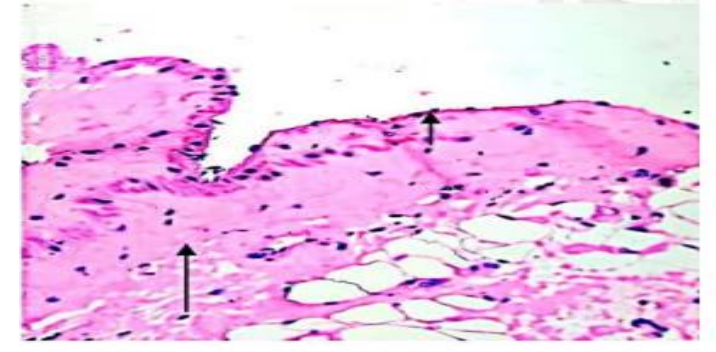

c)

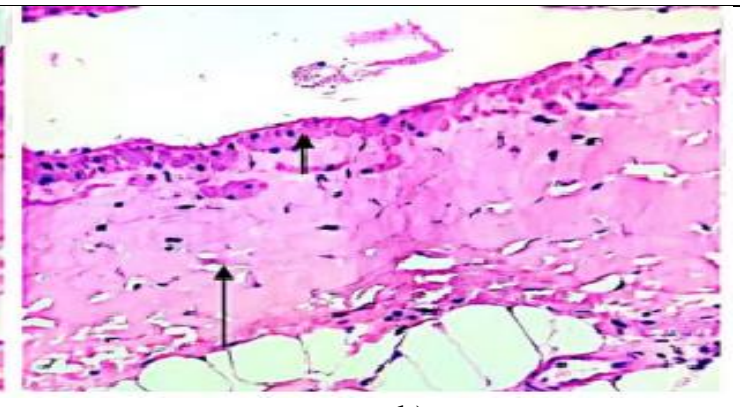

b)

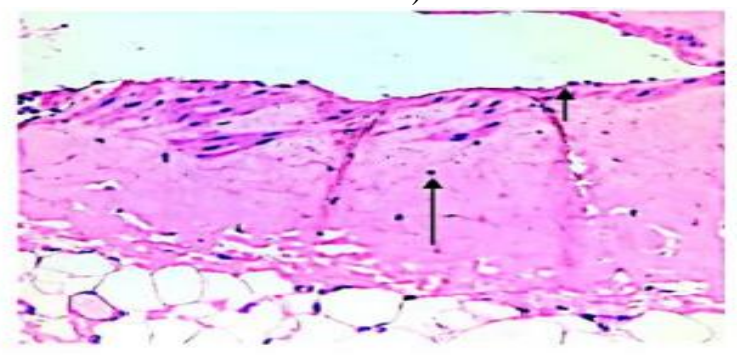

d)

\section{DISCUSSION}

Triton X-100 has been widely used to block the clearance of triglycerides rich lipoproteins to induce hyperlipidemia in experimental animals. The intraperitoneal injection of Triton X$100(100 \mathrm{mg} / \mathrm{kg})$ results significant increased in plasma cholesterol, TGs and LDL and make hyperlipidemic rats. This may be due to reduction in LDL and VLDL catabolism in liver.

The antihyperlipidemic activity of ethanol extract of Balanites aegyptiaca fruit (200 and $400 \mathrm{mg} / \mathrm{kg}$ ) against Triton X-100 shows a significant decrease in TC,HDL,LDL, TG $(\mathrm{P}<0.0014, \mathrm{P}<0.0040$, $\mathrm{P}<0.007,<\mathrm{P} 0.0004)$ and significant increase in HDL $(\mathrm{P}<0.001)$ in a dose dependent manner comparing with standard simvastatin treated group. However, there is a necessity for further research to work for more insight to the possible mechanisms.

The administration of ethanol extract of Balanites aegyptiaca fruit $400 \mathrm{mg} / \mathrm{kg}$ at evening $7 \mathrm{pm}$ showed more significantly normalizes the hyperlipidemic conditions by increasing HDL and decreasing triglyceride, total cholesterol, LDL levels and HDL levels when compared to low dose and triton X-100 treated hyperlipidemic rats.

Triton X-100 injected wistar albino rats resulted in increase in SGOT and SGPT levels. The administration of ethanol extract of Balanites aegyptiaca fruit 200 and $400 \mathrm{mg} / \mathrm{kg}$, has not shown altered liver biomarkers such as SGOT and SGPT. Therefore, the ethanol extract of Balanites aegyptiaca fruit is safe on long term use.

Triton X-100 injected wistar albino rats showed focal necrosis, periportal hepatocytes exhibit moderate chronic inflammation with focal steatosis and central veins and sinusoids were congested. The administration of ethanol extract of Balanites aegyptiaca fruit 200 and $400 \mathrm{mg} / \mathrm{kg}$, reverses the structural damages when compared to Triton X-100 treated group. It indicated to reduce the degeneration, inflammation and congestion for high dose.
Triton X-100 injected wistar albino rats showed intact endothelial lining with loss of integrity in the thickness of tunica intima and tunica adventitia. The tunica media appears poorly oriented with loss of elastic fibers. Low dose of ethanol extract of Balanites aegyptiaca fruit (200 mg/kg) administered rats showed focal loss of integrity in the thickness of tunica intima and tunica adventitia it indicate that Balanites aegyptiaca showed effect in artery wall with reduced in artery thickness. High dose of ethanol extract of Balanites aegyptiaca $(400 \mathrm{mg} / \mathrm{kg})$ administered rats showed intact endothelial lining with almost intact integrity in the thickness of tunica intima and tunica adventitia ,the tunica media appears oriented with intact elastic fibers.

The antihyperlipidemic activity of ethanol extract of Balanites aegyptiaca fruit could be due to phenolic and flavonoid present.

\section{CONCLUSION}

Based on our results, we concluded that ethanol extract of Balanites aegyptiaca fruit possess potent antihyperlipidemic activity and antioxidant activity. It does not have effect on liver markers. Chronotherapy of this reverses lipid profile histological structures more significantly than low dose. Therefore, it has more beneficial in the management of antihyperlipidemia conditions and associated diseases.

\section{REFERENCES}

[1] MOHAMMED. CVD, UK PU. 2015 SD. 2019;3(4TH OF JUNE):14.

[2] Sigma-Aldrich. Triton X-100 Technical Sheet. 1999;(X):2. https://www.sigmaaldrich.com/content/dam/sigmaaldrich/docs/Sigma/Product_Information_Sheet/1/t8532pis.pdf

[3] Saxon DR, Eckel RH. Statin intolerance: a literature review and management strategies. Prog Cardiovasc Dis. 2016;59:153-164. doi: 10.1016/j.pcad.2016.07.009. 
[4] Tirronen A, Hokkanen K, Vuorio T, Ylä-Herttuala S. Recent advances in novel therapies for lipid disorders. Hum Mol Genet. 2019;28(R1):R49-R54. doi:10.1093/hmg/ddz132

[5] Mensink RP, Aro A, Hond ED. PASSCLAIM - diet-related cardiovascular disease. Eur J Nutr. 2003;45:6-27.

[6] Effect of Partial Ileal Bypass Surgery on Mortality and Morbidity from Coronary Heart Disease in Patients with Hypercholesterolemia | Enhanced Reader.

[7] A.J. Alhassan, I.U. Muhammad, A. Idi, M. A. Danagmbo, Y. Ramatu, A. Mohammad, A. Nasir, A.I. Yaradua, S.M. Adamu IA. Phytochemical Screening and Proximate Analysis of Balanites aegyptiaca Kernel. Food Sci Qual Manag. 2018;74(May):1-6.

[8] Selvam P. Evaluation of Antidiabetic Activity of a Polyherbal Formulation in Alloxan Induced Diabetic Rats. 2010;1(9):82-87. www.ijpsr.com

[9] Al - Thobaiti SA, Zeid IMA. PHYTOCHEMISTRY AND PHARMACEUTICAL EVALUATION OF Balanites aegyptiaca: AN OVERVIEW. J Exp Biol Agric Sci. 2018;6(3):453-465. doi:10.18006/2018.6(3).453.465

[10] Luscher TF, Dohi Y, Tanner FC, Boulanger C. Endothelium-dependent control of vascular tone: effects of age, hypertension and lipids. Basic research in cardiology. 1991;86 Suppl 2:143-158. [PubMed].

[11] Molina-Cortés A, Sánchez-Motta T, Tobar-Tosse F, Quimbaya M. Spectrophotometric Estimation of Total Phenolic Content and Antioxidant Capacity of Molasses and Vinasses Generated from the Sugarcane Industry. Waste and Biomass Valorization. 2020;11(7):3453-3463. doi:10.1007/s12649-019-00690-1
[12] Creac'h P. Le Balanites ægyptiaca. Ses multiples applications au Tchad. Revue de botanique appliquée et d'agriculture coloniale. 1940;20(228);57893.

[13] G. Alemayehu. Physico- Chemical Characterization and Extraction of oilL from Balanites aegyptiaca plant (seed). World Journal of Pharmaceutical Research.2015;11(4);1723-32.

[14] Supekar AR, Kale AJ. Anti-Atherosclerosis Activity of Seed oil of Punica Granatum Linn in Triton X-100 induced hyperlipidemic rats . Material \& methods : 2015;3(10):1276-1280.

[15] Harikumar K, Niveditha B, Reddy Pavankumar M, Monica K, Gajendra P. Antihyperlipidemic activity of alcoholic \& methanolic extracts of Crotalaria juncea in triton WR-1339 induced hyperlipidemia. Int J Phytopharmacol 2012;3:256-262.

[16] Abdou HM, Yousef MI, Newairy AA. Triton WR-1339-induced hyperlipidemia, DNA fragmentation, neurotransmitters inhibition, oxidative damage, histopathological and morphometric changes: the protective role of soybean oil. J Basic Appl Zool. 2018;79(1). doi:10.1186/s41936-018-0065-Z

\section{AUTHORS}

First Author - Mohammed Adam Idris Hamad, Department of pharmacology,Nargund college of pharmacy

Second Author - Dr.Rama Nargund, Department of pharmacology,Nargund college of pharmacy 